\title{
Prevalence of frailty among elderly patients attending primary health care centers in sixth of October city
}

Eman Hosni Naeem ${ }^{1}$, Nayera Samy Mostafa ${ }^{2}$, Salma Mohamed Samir El-Said ${ }^{3}$.

Al hosary Family medical center, October, Giza, Egypt ${ }^{1}$

Community, Environmental and Occupational Medicine Department, Faculty of Medicine, Ain Shams University, Cairo, Egypt. $^{2}$

Geriatric Medicine and Gerontology Department, Faculty of Medicine, Ain Shams University, Cairo, Egypt. ${ }^{3}$

\section{Abstract}

Objectives: To determine the prevalence of frailty, reported in attendant elderly patients in primary health care centers in Sixth of October City in Greater Cairo.

Design: A Cross sectional study.

Setting and Participants: The study included 230 elder adults (both men and women), from 5 primary health care centers (PHCs) in 6th October city; 46 elders from each PHC.

Methods: All participants were questioned about their socio-demographic data by structured interview questionnaire and had physical examination. They were assessed using Comprehensive geriatric assessment; Daily and instrumental activities of daily living, Timed Up and Go test, Single leg stance test, hand-grip strength measurement, Mini-Mental Status Examination and mini-nutritional test

Results: Frailty was defined in the study according to modified Linda P Fried using 5 Frieds' criteria (unintentional weight loss more than $4.5 \mathrm{~kg}$ within in prior year, self -reported exhaustion, decreased grip strength, slow walking speed, low physical activity) The study participants were classified into non-frail, pre-frail and frail as $20.8 \%, 45.7 \%$ and $33.5 \%$ respectively. The mean age of frail participants was significantly higher than pre-frail and non-frail. Frailty was significantly more frequent among females $(74.03 \%)$. There was statistical positive correlation between frailty status and single leg balancing test, time up and go test and hand grip strength test.

Conclusion: The prevalence of frailty among our studied population was considerably high. Risk factors of frailty included female gender, weight loss, limited physical activity as per IADL assessment, and poor performance of Time Up and Go test and Single Leg Balance test. Additional predisposing factors to frailty are older age, illiteracy, low income, obesity, and depression.

Keywords: community-dwelling, Egypt, elderly, frailty, prevalence.

\section{Background}

Population ageing is accelerating rapidly worldwide, from 461 million people older than 65 years in 2004 to an estimated 2 billion people by 2050 . Frail older adults are a major, identifiable subset as they are vulnerable with appropriate subsequent evaluation and intervention constitutes a cornerstone of geriatric medicine and quality care for the ever-growing elderly population. Frailty is a disorder of several inter-related physiological systems. A gradual decrease in physiological reserve occurs with ageing, in frailty, this decrease is accelerated and homoeostatic mechanisms start to fail ${ }^{1}$.

Frailty has been defined by Fried et al. (2001). A condition meeting 3 of the 5 phenotypic criteria indicating compromised energetics namely, unintentional weight loss, exhaustion, low grip strength, slowed waking speed and low physical activity. A pre-frail stage, in which 1 or 2 criteria are present, identifies a subset at high risk of progressing to frailty. ${ }^{2}$ 
In Egypt, according to a study done on 83 Egyptian rural elderly in Dakahlia, it was found that nearly $24 \%$ of them were frail based on Study of Osteoporotic Fracture (SOF) frailty index ${ }^{3}$.

Frailty was $58.7 \%$ in study done for 312 elderlies in geriatric homes in Alexandria, Egypt according to Fried criteria ${ }^{4}$.

In Africa the prevalence of frailty above 60 years old range from $(5.4 \% \text { to } 13.2 \%)^{5}$.

In the United States the prevalence of frailty among adults aged 65 years and older (excluding nursing home residents) was estimated at $15.3 \%$, with $45.5 \%$ pre-frail according to a nationally representative profile done by Bandeen-Roche et al. $(2015)^{6}$.

Risk factors for frailty include; Female gender as women have been more likely than men to be characterized as frail in several studies ${ }^{3,4}$, lower socioeconomic status (SES) as measured by low education and/or low annual income, has been associated with frailty in several cross-sectional studies 6, 7 , poverty, living alone, area deprivation also considered as risk factor for frailty ${ }^{8}$. Physiologic Factors also considered as risk factor as the more physiological systems that are in a diminished state, the greater the likelihood of frailty $^{8,9}$ Depressive symptoms have been shown to be associated with the syndrome in cross-sectional analyses ${ }^{10}$.

Frailty has been associated with many diseases; cardiovascular disease, in particular ${ }^{11}$. Stroke, Diabetes, Hypertension, Arthritis, Cancer, and Chronic Obstructive Pulmonary Disease were predictive of incident frailty ${ }^{12}$.

Prevention of frailty encompasses three overlapping approaches across the lifespan: Primary prevention; increasing intrinsic capacity reserves in early aging. Secondary prevention; preserving function in late aging and tertiary prevention; restoring function in frail older adults. Care needs span across physical, environmental, and psychosocial domains, with the more frail patients having more unmet needs. ${ }^{13,14}$

In Egypt, studies on frailty prevalence and its assessment are scarce, our study, aimed to estimate the prevalence of frailty reported in attendant elderly patients in primary health care centers in Sixth of October City in Greater Cairo Governorate.

\section{Methods \\ Design: \\ Cross-sectional study \\ Study setting:}

Five primary health care centers in $6^{\text {th }}$ October city; (A1 Hosary, Al Shabab, Al Mostakbal, Al Reaya and Haram city primary health care).

\section{Study duration:}

Data was collected along a period of 6 months from October 2018 till March 2019. Two days were selected every week to fulfill the needed sample.

Study population:

230 older adults (both men and women) recruited 46 elders from 5 primary health care

\section{Sample size:}

Using PASS program, setting alpha error at 5\% and confidence interval width 0.08 . Based on result from previous study Collard et al. (2012) $)^{15}$, the prevalence of physical frailty was $9.9 \%$, taking in consideration $10 \%$ dropout note, the required sample was $\mathbf{2 3 0}$ elders.

Inclusion criteria:

Elders aged 60 years \& over both males and females.

\section{Exclusion criteria:}

1. Elders who suffered from any disability as handicapping or paralysis.

2. Elders who suffered from cognitive impairment diagnosed by mini mental state.

3. Elders who suffered from depression diagnosed by geriatric depression scale test 15-questions.

\section{Study tools:}

All participants were subjected to:

1. Socio-demographic data collection including age, gender, marital status, education, occupation, living condition, monthly income and history of special habits.

2. History of falls including any fall in the past, location of falling, injuries resulted from fall and fear of falling.

3. Comprehensive geriatric assessment ${ }^{16}$ by the following assessments:

- Assessment of depression ${ }^{17}$ using An Arabic version of $(\mathrm{GDS})^{18} 15$ items. It is effective for screening of depression in elders; in which participants were asked to respond by answering yes or no in reference to how they felt over the past week.

- Cognitive function was assessed ${ }^{19}$ using The Arabic version of Mini Mental Status Examination (MMSE) ${ }^{20}$. The MMSE takes 510 minutes. It's an 11 questions tool to measure five areas of cognitive function: orientation to time, orientation to place, three words registration, attention and calculation, three words recall, language and visual construction (pentagon copying). The score for MMS ranges from 0 - 30 according to age \& level of education with lower score reflecting worse cognitive function according to age \& educational level.

- Assessment of physical activity by instrumental activity of daily living (IADL) ${ }^{21}$, 22 and activity of daily living (ADL) ${ }^{23}, 24$. Participants' functional level was then categorized as independent, assisted or dependent accordingly.

- Assessment of walking speed by time up and go test (TUG) ${ }^{25}$ evaluate the gait and risk of fall. It measured the time of every participant taking to rise from a chair, walk 3 meters distance, turn, walking back to the chair and 
sit-down. The time in seconds started with the word (START) and ended when the participant sits-down. A score of more than 14 seconds indicates high risk of falls.

- Assessment of strength by hand grip test ${ }^{26}$ Using Camry digital hand dynamometer. The participant can squeezes with maximum isometric effort for at least 5 second, the screen will display the maximum grip value and a grip value status bar showing the status of weak, strong or normal according to age \& gender.

- Assessment of exhaustion by multidimensional assessment of fatigue (MAF) 27. It is 16 items scale that measures fatigue according to degree \& severity over the past week \& its impact on various activity of daily living (household chores, cooking, bathing, dressing, working, socializing, sexual activity, leisure, shopping, walking \& exercising) and the last two questions are about the timing \& distress that cause the fatigue.

- Assessment of balance by Single Leg Balance test ${ }^{28}$. The participant stands erect on firm surface and look forward with arms folded, using chair for initial support. The timer starts once the foot is lifted off the floor and stops when the participant raises foot or touches the floor or with arm movements. Score of more than 10 seconds or equal is normal.

- Assessment of nutrition by mini-nutritional test (short form) (MNA) ${ }^{29}$. Using an Arabic version ${ }^{30}$ which is composed of six questions about (loss of food in-take, weight loss, mobility assessment, neuropsychological problems, acute disease \& body mass index). Score Less than 8 indicates malnutrition.

\section{Ethical consideration:}

- Approval from faculty of medicine Ain Shams University ethical committee was obtained.

- Administrative approvals from the directors of each primary health care centers were obtained.

- Verbal informed consent was taken from every participant after explaining the purpose of the study.

\section{Data Management and Analysis:}

The collected data was revised, coded, tabulated and introduced to a PC using Statistical package for Social Science (SPSS 25). Data was presented and suitable analysis was done according to the type of data obtained for each parameter.

\section{i. Descriptive statistics:}

1. Mean and Standard deviation $( \pm S D$ ) for parametric numerical data, while Median and Interquartile range (IQR) for non-parametric numerical data.

2. Frequency and percentage of non-numerical data.

ii. Analytical statistics:

1. Student $\boldsymbol{T}$ test was used to assess the statistical significance of the difference between two study group means.

2. ANOVA test was used to assess the statistical significance of the difference between more than two study group means.

3. Post Hoc test is used for comparisons of all possible pairs of group means.

4. The Kruskal-Wallis test is was used to assess the statistical significance of the difference between more than two study group ordinal variables.

5. Chi-Square test was used to examine the relationship between two qualitative variables

6. Fisher's exact test was used to examine the relationship between two qualitative variables when the expected count is less than 5 in more than $20 \%$ of cells.

7. Logistic regression: used to adjust the prediction of the presence or absence of an outcome based on a set of independent variables. It is similar to a linear regression model but is suited when the dependent variable is qualitative (categorical)

\section{$P$ - value: level of significance}

- $\quad P<0.05$ : Significant (S).

- $\quad \mathrm{P}<0.01$ : Highly significant (HS).

\section{Results:}

The study sample consisted of 230 elderly participants. Approximately half of the participants were females $(55.7 \%)$. About $35 \%$ experienced more than 9 years of education, while $27.4 \%$ were illiterate. $57 \%$ of the study participants were married and $95.2 \%$ lived in the apartment. About $60 \%$ of the participants had a monthly income less than 1000 L.E, $73.5 \%$ were nonsmokers and only $18.3 \%$ were currently working.

Frailty according to modified Fried using 5 Fried's criteria; reported as non-frail, pre-frail and frail in percent; $(20.8 \%, 45.7 \%$ and $33.5 \%)$ respectively. Exhaustion, balance impairment and low physical activity by IADL were the most frequent symptoms of frailty among all participants $(72.6 \%, 63.5 \%$ and $66.57 \%$ ) respectively.

The mean age of frail participants was significantly higher than pre-frail and non-frail. Frailty was significantly more frequent among females $(74.03 \%)$ than males. It was significantly higher among widows (70.13\%), among those who are living with others $(66.23 \%)$ and those who are living in apartment $(100 \%)$. Frailty was more prevalent among illiterate $(57.14 \%)$, unemployed $(70.13 \%)$ and who had income of 1000 L.E or less $(79.22 \%)$. Smoking frequency was $28.57 \%$ among pre-frail and $10.39 \%$ among frail participants. (Table 1) and(Table 2)

There was statistical correlation between frailty status and single leg balancing test, time up and go test, hand grip strength and function level using IADL an ADL tools with ( $\mathrm{P}<0.001$ ) for all tests. 
Table (1): Association between socio-demographic data and the three frailty groups

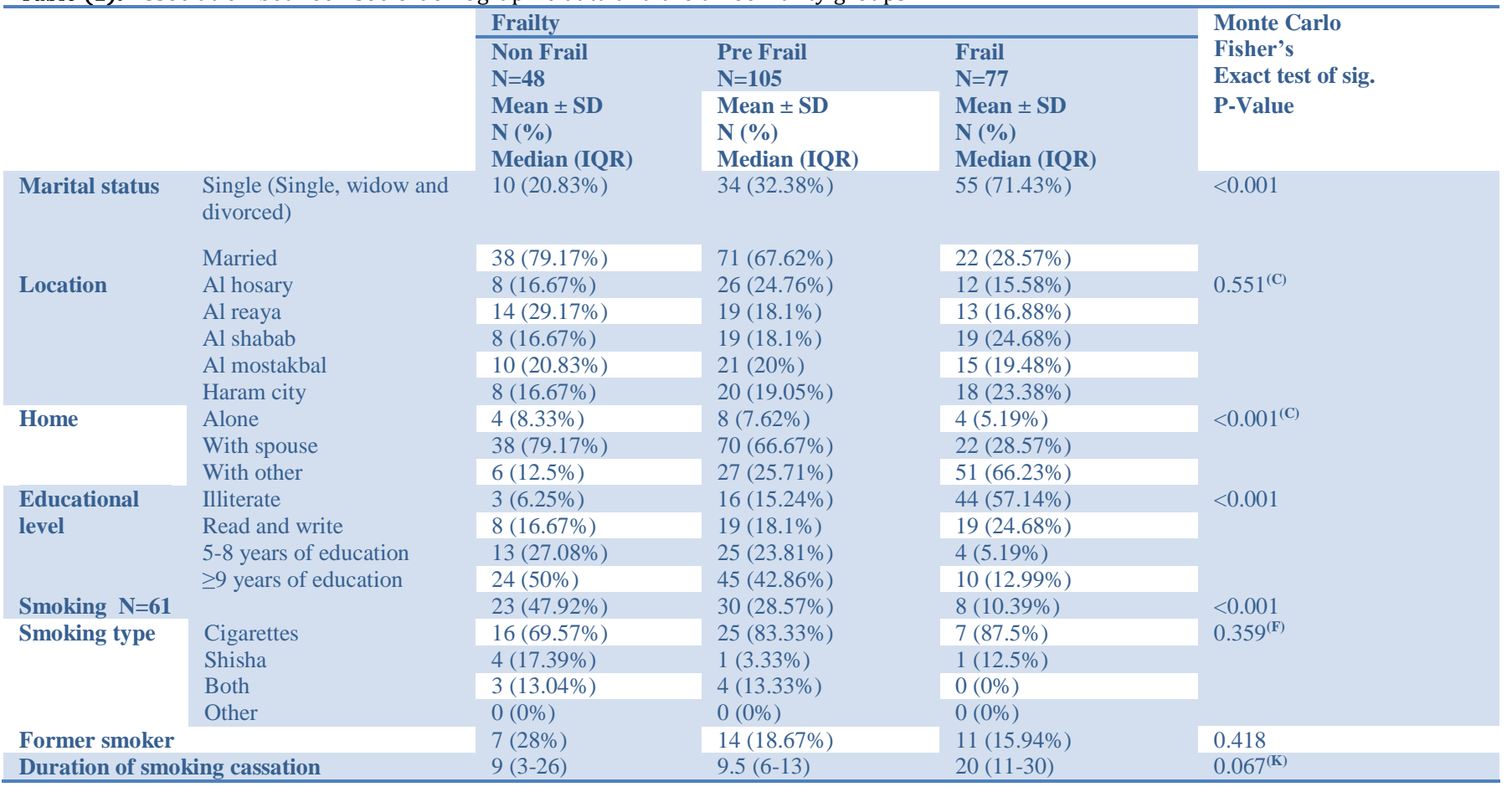

Table (2): Prevalence of frailty elements among the participants.

\begin{tabular}{|c|c|c|c|c|c|}
\hline Six modified fried elements & & $\mathbf{N}$ & & $\%$ & \\
\hline Unintentional weight loss $>\mathbf{3 k g}$ & Positive & 2 & & $0.9 \%$ & \\
\hline Exhaustion & Positive & 167 & & $72.6 \%$ & \\
\hline Weakness & Positive & 52 & & $22,6 \%$ & \\
\hline Slow gait & Positive & 72 & & $31.3 \%$ & \\
\hline \multirow[t]{2}{*}{ Balance impairment } & Positive & 146 & & $63.5 \%$ & \\
\hline & & IADL & ADL & IADL & ADL \\
\hline Low physical activity by IADL and ADL & Positive & 153 & 43 & $66.57 \%$ & $18.77 \%$ \\
\hline
\end{tabular}

Table (3): Comparison between the three frailty groups as regard comprehensive geriatric assessment tools.

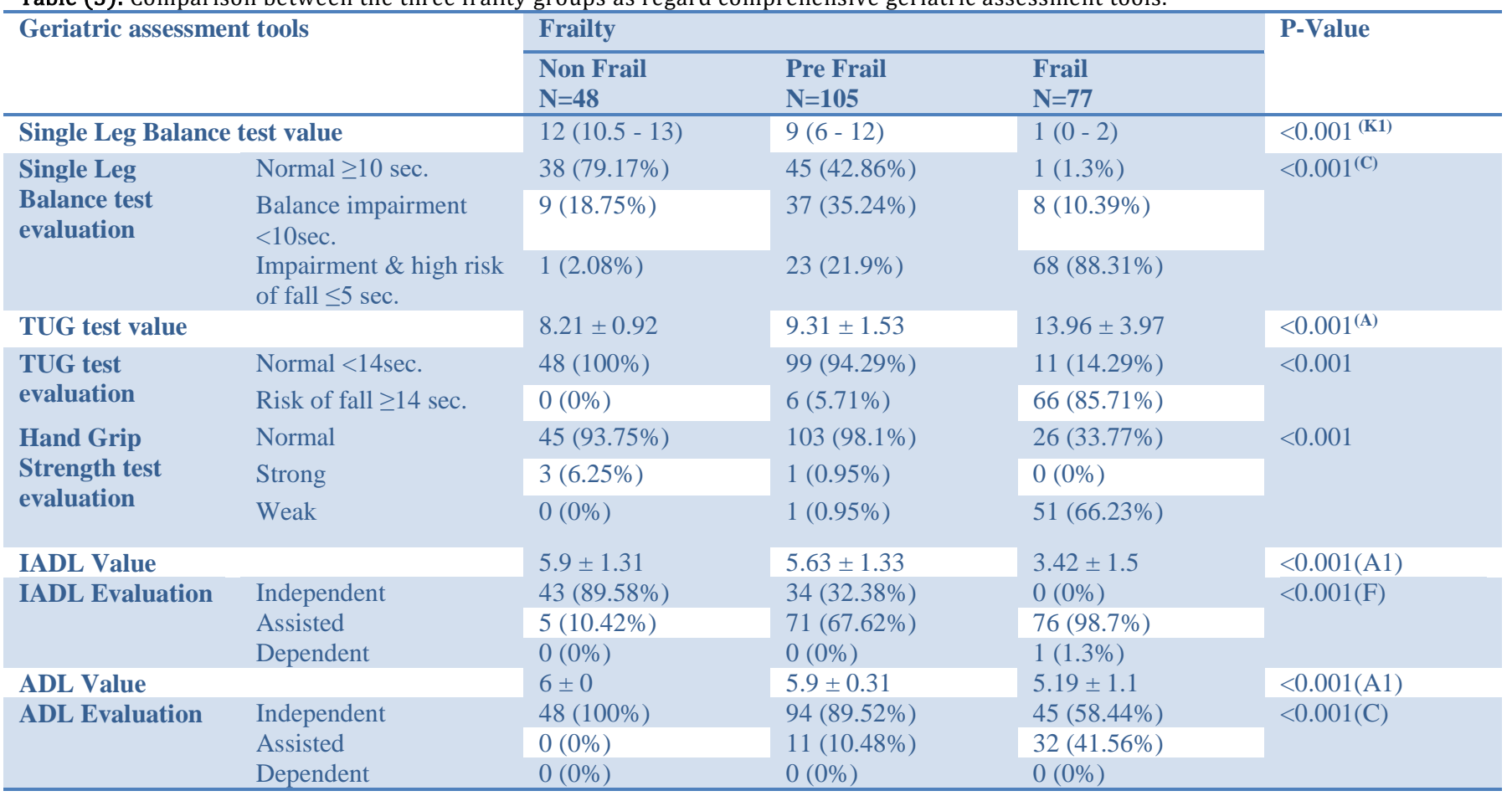

(A) One Way ANOVA test of significance, post hoc Bonferroni test was significant at: (A1) Frail group Vs. (Non frail and Pre frail groups.) (F) Monte Carlo Fisher's Exact test of significance. (C) Chi-Square test of significance. (K) Kruskal-Wallis test of significance, post hoc was significant at: (K1) Between all groups. 
$98.7 \%$ of frail participants stand on one leg less than 10 seconds, $85.71 \%$ of them had the worst results of time up and go test and $66.23 \%$ were weak using hand grip strength test.

$98.7 \%$ of frail participants were assisted using an IADL tool, while $41.56 \%$ of them were assisted using ADL tool. (Table 3)

Binary logistic regression analysis for risk factors of frailty shows that the strongest predictors were increasing age, female gender, malnutrition, low physical activity assessed by IADL and ADL, balance impairment and slow gait. (Table 4)

Table (4): Regression analysis of frailty predictors.

\begin{tabular}{|l|l|l|}
\hline & p value & Odds Ratio (95\% CI) \\
\hline Increase Age & 0.199 & $1.09(0.96-1.23)$ \\
\hline Gender (REF. male) & 0.032 & $7.4(1.19-45.91)$ \\
\hline Nutrition assessment & 0.020 & $0.24(0.07-0.8)$ \\
\hline GDS & 0.677 & $1.08(0.74-1.58)$ \\
\hline IADL & 0.001 & $0.32(0.16-0.64)$ \\
\hline ADL & 0.342 & $2.02(0.47-8.57)$ \\
\hline Single Leg Balance test & 0.008 & $0.76(0.62-0.93)$ \\
\hline Time Up and Go test & 0.003 & $1.63(1.18-2.25)$ \\
\hline
\end{tabular}

\section{DISCUSSION}

Frailty is one of the most challenging health problems that affect the elderly. It affects the quality of life, and physical wellbeing. Moreover, it threatens one's independence. Unfortunately, the prevalence of frailty among the elderly in Egypt is barely known.

In our study, the prevalence of frailty was $33.5 \%$, with approximately half of the participants falling in the prefrailty group. Many studies were published supporting this finding with a similar incidence among larger sample sizes and huge variability among the studied populations. This agrees with Thompson et al. found that the incidence of frailty is $34 \%$ among community dwellers older adults ${ }^{31}$.

Whilst many other studies reported a much lower incidence rate reaching less than $10 \%$. For instance, Wang et al., Swiecicka et al., Lorenzo-lopez et al., and Doi et al., claimed an incidence rate of $4.2 \%, 5.2 \%$, and $6 \%$, and $8 \%$, respectively ${ }^{32-35}$.In contrast, a higher prevalence was reported by Tayel and Elkady where they found that $58.7 \%$ of the elderly residents in geriatric homes in Alexandria, Egypt were frail ${ }^{36}$ and Sabbour et al study depicted a much higher prevalence. During their investigations about the prevalence of frailty and malnutrition among two groups; nursing homes and community dwellers. They found that prevalence of frailty according to the SHARE frailty index was about $71.7 \%$ of the elderly participants, whereas $22.6 \%$ were considered as prefrail ${ }^{37}$. This huge discrepancy in incidence rates / prevalence rates among different studies is attributed to many factors including study settings "eg:our participants were collected from
PHC units and other studies collected participants from geriatric homes", study population, sample size, and assessment tools. There is an association between all these factors and the different risk of frailty and prefrailty among the elderly ${ }^{38}$.

In the current study, exhaustion, low physical activity, and balance impairment were the most frequent symptoms of frailty criteria $(72.6 \%, 66.5 \%$, and $63.5 \%$, respectively). This relatively disagrees with Sabbour et al. who found that weakness un measurable and exhaustion were the most frequent reported symptoms 39. Findings from Tayel and Elkady study also contradicted ours. They claimed that the most prevalent lty criteria were slow walking speed, low physical vity, and muscle weakness $(90.2 \%, 81.9 \%$, and $3 \%$, respectively) ${ }^{36}$.

$\mathrm{s}$ is in line with other studies, which showed that lty was most commonly associated with lower scle strength, poor physical performances, and sequent feeling of exhaustion and therefore reduced 'sical activity ${ }^{40}$.

: present study group age (ranges; 60 - 90 years) h mean age of $(66.84 \pm 5.86)$, this age near to that of itell et al. who had sample of up 1,327 individuals $\mathrm{n}$ the Madrid neighborhoods of Peñagrande and undtro Caminos. The mean age was $75.4 \pm 7.4$ (range: 65-104). ${ }^{41}$ and with A cross sectional study was conducted on 312 elders of both sexes, aged between $60-80$ years, of mean age $70.79 \pm 7.7$ years elderly homes in Alexandria, Egypt ${ }^{36}$.On other hand in Northern Italy study population done by Perna et al. of 366 participants had a mean age of $(81.46 \pm 6.55)$ who had higher range of age than current study as they had high life span ${ }^{42}$

In spite the fact that few of our participants were dependent, almost all of frail participants needed assistance in daily life activities $(98.7 \%)$, while more than half $(67.6 \%)$ of those pre-frail need it too. These figures are higher in comparison to other studies. For instance, Yadav et al., found that approximately half of their studied participants needed assistance in daily living activities ${ }^{43}$.

Findings from Akın et al study augmented this finding as $47.1 \%$ of elderly and frail primary health care users were ADL dependent ${ }^{44}$.Further analysis proved that there was a statistically significant relationship between frailty status and function level using IADL an ADL tools.

In our study, several factors were considered predictors or risk factors for frailty. This includes female gender, poor nutrition status, restricted daily life activities, poor performance during Time Up and Go test and Single Leg Balance test.

We found that nearly three fourths of our frail participants were females. This is on agreement with many studies ${ }^{45}, 46$.Female gender is associated with more health comorbidities, including osteoarthritis, anxiety, depression, imbalance disorders, and many other health conditions. This gender specific affection 
is explained by multiple causes; on the top of them is overrepresentation and reporting since females tend to seek health care more often than males. Others would blame the low physiological reserve due to menstruation, and pregnancy, in addition to the chronic health conditions ${ }^{47}$.

It was noticed that frailty was more prevalent among subjects with low income $<500$ L.E. It is already established that income status determines some health conditions, frailty is one of them. Yadav et al reported a $65 \%$ incidence of frailty among those with low income. Old people with low income can barely have access to good health care facilities. Poor medical care seeking leads to buildup of multiple health conditions contributing to the overall risk of frailty ${ }^{43}$

We found that $23 \%$ of our frail subjects had restricted movement and could not leave home. Assessment of the physical activity in using IADL showed that $33.5 \%$, $66.1 \%$ and $0.4 \%$ of the participants were independent, assisted, and dependent respectively. People with poor performance on IADL assessment are 0.32 times riskier to have frailty.

This disagrees with Ebeid. et al study who found that $73.9 \%, 13.6 \%$ and $1.1 \%$ were independent, assisted, and dependent respectively. Regarding ADL, none of our frail subjects proved to be dependent; yet, approximately half of them were assisted. Similarly, in Ebeid. et al study, none of their participants were dependent; but assisted individuals were fewer than ours $18.7 \%{ }^{48}$. In contrast, in Setiati et al study, reported a higher percentage of dependent individuals reaching $26 \%{ }^{49}$.

This variability in ADL scores is attributed to the variability of the mean age of the included patients. It was noticed that the older the individuals, the higher their susceptibility to dependency.

When gait speed was assessed, we found abnormal result in $88 \%$ of frail people, while slowness itself was proved in $22 \%$ of them. Individuals with slow gat are 1.6 times liable to frailty. This proves that frailty is associated with poor performance in Timed Up and Go test. This is low in comparison to Lourenço et al study who found that slow gait speed was evident among $95.5 \%$ of frail individuals ${ }^{50}$.Slowness is one of the indicators of frailty, which impedes the individual's physical activity, mobility, and quality of life. Moreover, it affects the psychological status of the elderly.

\section{CONCLUSION}

The prevalence of frailty among our studied population was considerably high. Risk factors of frailty included female gender, malnutrition, limited physical activity as per IADL assessment, and poor performance of Time Up and Go test and Single Leg Balance test. Additional predisposing factors to frailty are older age, illiteracy, low income, obesity, and depression.

\section{LIMITATION}

Part of questionnaire of the current study is based on self-reported information which may be affected by memory and information bias due to educational disparities. We collected our participants from PHC units and this make less Varity in our participants and results

\section{References}

1. Clegg A, Young J, lliffe S, Rikkert MO and Rockwood K. Frailty in elderly people. The Lancet. 2013; (381): 752-62.

2. Fried LP, Tangen CM, Walston J, et al. Frailty in older adults: evidence for a phenotype. The journals of gerontology Series A, Biological sciences and medical sciences. 2001; (56): M146-56.

3. Ebeid SM, RM Ea, MA K, NE S and NF AE. Frailty prevalence and correlates among free living elderly in an Egyptian rural elderly. IJRSR. 2016; (7): 8902-7.

4. Tayel DI and El-Kady HM. Frailty in Relation to Poor Dietary Intake among Institutionalized Elders in Alexandria, Egypt. IJAST, 2016.

5. Payne CF, Wade A, Kabudula CW, et al. Prevalence and correlates of frailty in an older rural African population: findings from the HAALSI cohort study. BMC geriatrics. 2017; (17): 293.

6. Bandeen-Roche K, Seplaki CL, Huang J, et al. Frailty in older adults: a nationally representative profile in the United States. The Journals of Gerontology: Series A. 2015; (70): 1427-34

7. Blaum CS, Xue QL, Michelon E, Semba RD and Fried LP. The association between obesity and the frailty syndrome in older women: the Women's Health and Aging Studies. Journal of the American Geriatrics Society. 2005; (53): 927-34.

8. Cesari M, Vellas B and Gambassi G. The stress of aging. Experimental gerontology. 2013; (48): 451-6.

9. Gielen E, Verschueren S, O'Neill T, et al. Musculoskeletal frailty: a geriatric syndrome at the core of fracture occurrence in older age. Calcified tissue international. 2012; (91): 161-77.

10. Tesch-Römer C and Wahl H-W. Toward a more comprehensive concept of successful aging: disability and care needs. The Journals of Gerontology: Series B. 2017; (72): 310-8.

11. Ferrucci $L$ and Fabbri E. Inflammageing: chronic inflammation in ageing, cardiovascular disease, and frailty. Nature Reviews Cardiology. 2018; (15): 505

12. Espinoza SE and Fried LP. Risk factors for frailty in the older adult. Clinical Geriatrics. 2007; (15): 37.

13. Vellas B and Sourdet S. Prevention of frailty in aging. J Frailty Aging. 2017; (6): 174-7.

14. Hoogendijk EO, Muntinga ME, van Leeuwen KM, et al. Selfperceived met and unmet care needs of frail older adults in primary care. Archives of gerontology and geriatrics. 2014; (58): 37-42.

15. Collard RM, Boter H, Schoevers RA and Oude Voshaar RC. Prevalence of frailty in community-dwelling older persons: a systematic review. Journal of the American Geriatrics Society. 2012; (60): 1487-92.

16. de Sousa MAR. Tratamento do cancro da mama na mulher em idade geriátrica. 2014

17. Wongpakaran N, Wongpakaran $T$ and Van Reekum R. The use of GDS-15 in detecting MDD: a comparison between residents in a Thai long-term care home and geriatric outpatients. Journal of clinical medicine research. 2013; (5): 101.

18. Metwally A, El-Banouby M, Mortagy A and Ghanem M. Prevalence of depression among Egyptian geriatric community. Faculty of Medicine, Ain Shams University. 1998.

19. Votruba KL, Persad C and Giordani B. Cognitive deficits in healthy elderly population with "normal" scores on the Mini-Mental State Examination. Journal of geriatric psychiatry and neurology. 2016; (29): 126-32.

20. El-OkI M, El Banouby $M$ and El Etrebi A. Prevalence of Alzheimer dementia and other causes of dementia in Egyptian elderly. MD thesis, faculty of medicine, Ain Shams University. 2002

21. Lawton MP and Brody EM. Assessment of older people: selfmaintaining and instrumental activities of daily living. The Gerontologist. 1969; (9): 179-86.

22. Fillenbaum GG and World Health 0 . The wellbeing of the elderly : approaches to multidimensional assessment / Gerda G. Fillenbaum. Geneva: World Health Organization, 1984. 
23. Katz S. Assessing self-maintenance: activities of daily living, mobility, and instrumental activities of daily living. J Am Geriatr Soc. 1983; (31): 721-7.

24. El-Sherpiny M, Mortagy $A$ and Fahy $H$. Prevalence of hypercholesterolemia among elderly people living in nursing houses in Cairo. Geriatric Department Library, Ain Shams University, Cairo. 2000; (6).

25. Podsiadlo D and Richardson S. The timed "Up \& Go": a test of basic functional mobility for frail elderly persons. Journal of the American geriatrics Society. 1991; (39): 142-8.

26. Butler Forslund E. Falls in wheelchair users with spinal cord injury: incidence, risks and concerns. 2017.

27. Belza BL, Henke CJ, Yelin EH, Epstein WV and Gilliss CL. Correlates of fatigue in older adults with rheumatoid arthritis. Nursing research. 1993.

28. Kouvelioti V, Kellis E, Kofotolis N and Amiridis I. Reliability of single-leg and double-leg balance tests in subjects with anterior cruciate ligament reconstruction and controls. Research in Sports Medicine. 2015; (23): 151-66.

29. Rubenstein LZ, Harker JO, Salva A, Guigoz $Y$ and Vellas B. Screening for undernutrition in geriatric practice: developing the short-form mini-nutritional assessment (MNA-SF). The journals of gerontology Series A, Biological sciences and medical sciences. 2001; (56): M366-72.

30. Al-Atty A, Muhammad F, Abou Hashem RM and Abd Elaziz $\mathrm{KM}$. Prevalence of malnutrition in recently hospitalized elderly in Cairo using a valid and reliable short form of Arabic version of Mini-Nutritional Assessment (MNA-SF-A). Middle East Journal of Age and Ageing. 2012; (83): 1-5.

31. Thompson $M Q$, Theou $O$, Adams RJ, Tucker $G R$ and Visvanathan R. Frailty state transitions and associated factors in South Australian older adults. Geriatrics \& gerontology international. 2018; (18): 1549-55.

32. Wang M-C, Li T-C, Li C-I, et al. Frailty, transition in frailty status and all-cause mortality in older adults of a Taichung communitybased population. BMC geriatrics. 2019; (19): 26.

33. Swiecicka A, Eendebak RJ, Lunt $M$, et al. Reproductive hormone levels predict changes in frailty status in community-dwelling older men: European Male Ageing Study prospective data. The Journal of Clinical Endocrinology \& Metabolism. 2018; (103): 701-9.

34. Lorenzo-López L, López-López R, Maseda A, Buján A, Rodríguez-Villamil JL and Millán-Calenti JC. Changes in frailty status in a community-dwelling cohort of older adults: The VERISAÚDE study. Maturitas. 2019; (119): 54-60.

35. Doi T, Makizako H, Tsutsumimoto K, et al. Transitional status and modifiable risk of frailty in Japanese older adults: A prospective cohort study. Geriatrics \& Gerontology International. 2018; (18): 1562-6.

36. Tayel DI and Elkady HM. Frailty in relation to poor dietry intake among institutionalized elders in alexandria, Egypt. International Journal of Advanced Scientific and Technical Research 2016; (1): 404-14. 37. Sabbour SM, Rahamn SAA, Amin GEE and Mohamed BA. Frailty and malnutrition among Egyptian elderly: prevalence and risk factors in nursing home and community dwelling elderly. EJGG. 2018; ( 5): 27- 31.

38. Ofori-Asenso R, Chin KL, Mazidi M, et al. Global incidence of frailty and prefrailty among community-dwelling older adults: a systematic review and meta-analysis. JAMA network open. 2019; (2): e198398-e.

39. Sabbour SM, Rahamn A, Ahmed S, Amin GEE and Mohamed BA. Frailty and malnutrition among Egyptian elderly: prevalence and risk factors in nursing home and community dwelling elderly. The Egyptian Journal of Geriatrics and Gerontology. 2018; (5): 1-5.

40. Bonnefoy M, Berrut $\mathrm{G}$, Lesourd $\mathrm{B}$, et al. Frailty and nutrition: searching for evidence. The journal of nutrition, health \& aging. 2015; (19): $250-7$.

41. Castell M-V, Sánchez M, Julián R, Queipo R, Martín S and Otero Á. Frailty prevalence and slow walking speed in persons age 65 and older: implications for primary care. BMC Family Practice. 2013; (14): 86.

42. Perna S, Francis MDA, Bologna $C$, et al. Performance of Edmonton Frail Scale on frailty assessment: its association with multidimensional geriatric conditions assessed with specific screening tools. BMC Geriatr. 2017; (17): 2.

43. Yadav UN, Tamang MK, Thapa TB, Hosseinzadeh H, Harris MF and Yadav KK. Prevalence and determinants of frailty in the absence of disability among older population: a cross sectional study from rural communities in Nepal. BMC geriatrics. 2019; (19): 283

44. Akın S, Mazıcıoglu MM, Mucuk S, et al. The prevalence of frailty and related factors in community-dwelling Turkish elderly according to modified Fried Frailty Index and FRAIL scales. Aging clinical and experimental research. 2015; (27): 703-9.

45. Kendhapedi KK and Devasenapathy N. Prevalence and factors associated with frailty among community-dwelling older people in rural Thanjavur district of South India: a cross-sectional study. BMJ open. 2019; (9): e032904.

46. Carneiro JA, Ramos GCF, Barbosa ATF, de Mendonça JMG da Costa FM and Caldeira AP. Prevalence and factors associated with frailty in non-institutionalized older adults/Prevalência e fatores associados à fragilidade em idosos não institucionalizados/Prevalencia y factores asociados a la fragilidad en ancianos no institucionalizados. Revista brasileira de enfermagem. 2016; (69): 408.

47. Navarro-Pardo E, Villacampa-Fernández P, Hubbard RE and Gordon E. Frailty and Comorbidities. Frailty in Women. Menopause. Springer, 2017, p. 303-15.

48. Ebeid. SM, akkad. RME, Kamel MA, E.Shafeek $\mathrm{N}$ and elezz NFA. Frailty prevalence and correlates among free living elderly in an Egyptian rural elderly. International Journal of Recent Scientific Research. 2016; (7): 8901-7.

49. Setiati S, Laksmi PW, Aryana IS, et al. Frailty state among Indonesian elderly: prevalence, associated factors, and frailty state transition. BMC geriatrics. 2019; (19): 182.

50. Lourenço RA, Moreira VG, Banhato EFC, et al. Prevalence of frailty and associated factors in a community-dwelling older people cohort living in Juiz de Fora, Minas Gerais, Brazil: Fibra-JF Study. Ciencia \& saude coletiva. 2019; (24): 35-44. 